\title{
OD NADWARCIAŃSKIEGO MATECZNIKA KU ARCHEOLOGII POGRANICZA ZACHODU I WSCHODU EUROPY*
}

Normą jest, iż w procesie formowania europejskich ośrodków archeologicznych ich twórcy, w swoich konstrukcjach założycielskich, zarysowywali wymiary przestrzennej działalności (mezoregionalny, makroregionalny, kontynentalny, ,zewnętrzny”, np. Bliskiego Wschodu czy Eurazji). Parametry te były pochodną lokalnych odczuć - ambicji, lub też uzewnętrznieniem racji stanu Państw, w obrębie których dane centra naukowe były tworzone lub funkcjonują aktualnie. W tym drugim przypadku język - aktywność Państwa daje się odczuć wielokrotnie pod przykrywką sieci, dotowanych czy wspieranych przez nie: grantów, stypendiów i staży (np. w ramach fundacji, czy też stowarzyszeń) oraz stymulacji prawnych. Mogą one przybierać charakter ponadnarodowy, wiążąc środowiska naukowe w złożone zależności sieci ośrodków, możliwych do opisu w kategoriach relacji: centrum a ośrodki klientalne (zależności te mogą wystąpić, lecz nie muszą). Uwagi niniejsze dotyczą wyborów dróg w ramach zarysowanych powyżej doświadczeń w kręgu osób odpowiedzialnych za rozwój poznańskiego ośrodka archeologicznego.

\section{POZNAŃ W DOBIE ODZYSKANIA NIEPODLEGLOŚCI: ODCZUCIA/AMBICJE I RACJA STANU}

Gdy 7 maja w 1919 r., w ramach powstającego Uniwersytetu Poznańskiego, Profesor Józef Kostrzewski tworzył Instytut Archeologii Przedhistorycznej (przemianowany niebawem na Instytut Prehistorii) oczywistą strategią w koncepcji przestrzennej jego rozwoju wyznaczały Kresy Zachodnie II Rzeczpospolitej; a w ich zagospodarowaniu naukowym rolę kluczową odgrywał Wielkopolski - Nadwarciański Matecznik (ryc. 1: 2). Wybory te dokumentuje dorobek Ojca Założyciela, jak też plany naukowe Jego uczniów. W kategorii uzasadnionych odstępstw od tej normy programowej wymienić można dwa przypadki ,zewnętrznych” akcji terenowych, dotyczące Pomorza Gdańskiego i Górnego Śląska ${ }^{1}$.

\footnotetext{
${ }^{*}$ Niniejszy tekst powstał na podstawie referatu wygłoszonego na jubileuszowej sesji 90-lecia Instytutu Prahistorii UAM, która odbyła się w lipcu 2009, w Obrzycku.

${ }^{1}$ Żak 1972, s. 19 n.
} 


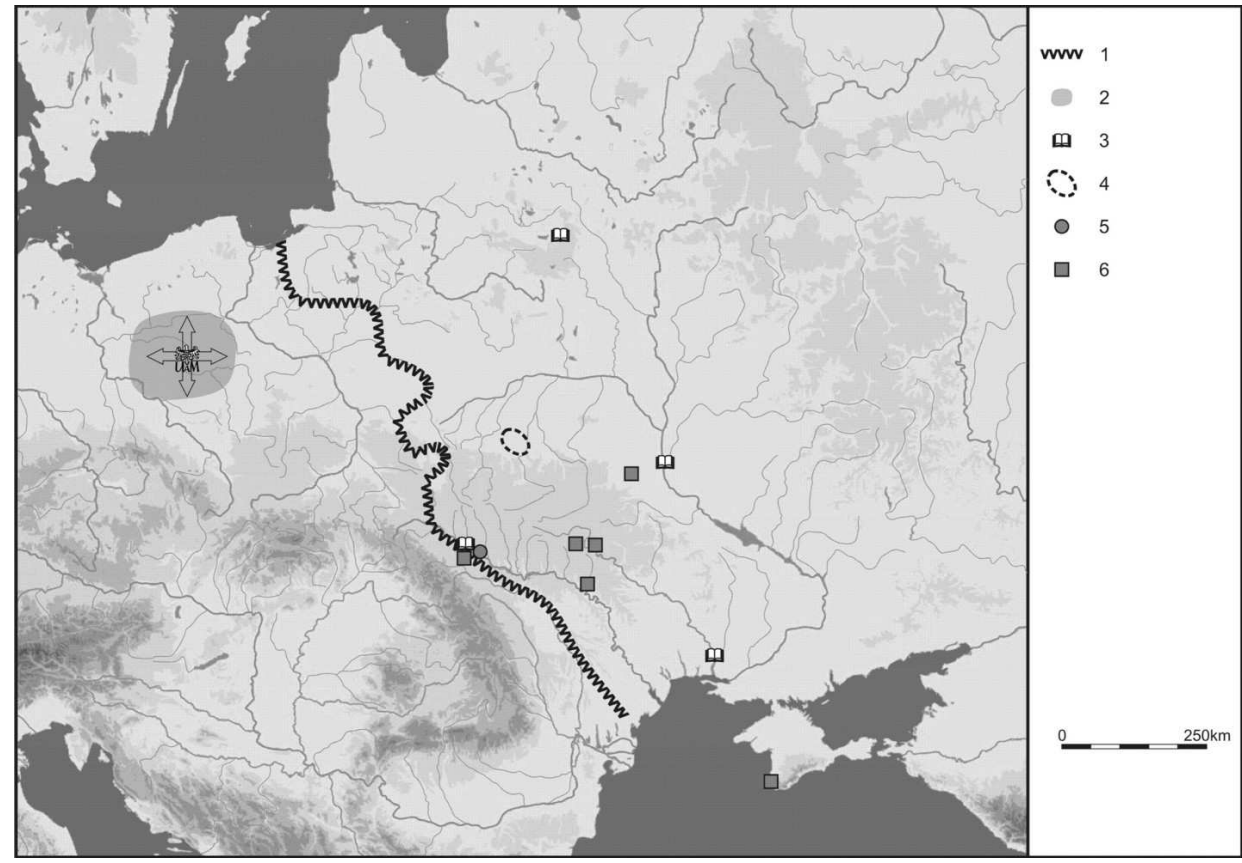

Ryc. 1. Pogranicze biokulturowe Zachodu i Wschodu Europy

Legenda: 1 - rozgraniczenie fizyczno-geograficzne Zachodu i Wschodu Europy (tzw. limes bużańsko-dniestrzański); 2 - „nadwarciański matecznik” poznańskiego ośrodka archeologicznego; 3 - ośrodki archeologiczne na obszarach Białorusi i Ukrainy współpracujące, w ramach umów dwustronnych, z Instytutem Prahistorii UAM; 4, 5 - por. 6; stanowiska i strefy na terytorium Ukrainy badane terenowo przez archeologów z Instytutu Prahistorii UAM (4 - wołyńskie złoża bazaltów oraz miedzi; 5 - Biały Potok, badania J. Kostrzewskiego; 6 - stanowiska badane w XXI w., por. tekst)

Wyjątkiem w tej skali programowej pozostaje inicjatywa wykopaliskowa w zlewni Dniestru - w Białym Potoku². Ten ostatni epizodyczny program - powstały w 1925 r. można uznać za symboliczną antycypację strategii poszerzania poznańskiej ,,przestrzeni kanonicznej”, jakiej rozwój obserwujemy aktualnie.

Lata powojenne, $\mathrm{PRL}^{3}$ - przynajmniej do cezury obchodów millenialnych - utwierdzały efektywność komentowanego wyboru (por. „kresowe hasło”: ,jesteśmy, byliśmy, będziemy" na Ziemiach Zachodnich - Odzyskanych). Na rozwój archeologii bezpośredni wpływ miała w tym okresie racja stanu - odniesienia do dyskusji nad legalizmem granicy na Odrze i Nysie Łużyckiej, prace badawcze skoncentrowano na problematyce państwa piastowskiego, na jego wizerunku politycznym i cywilizacyjnym. Wątek wschodni można wtedy było dostrzec w wymiarze drugorzędnym, w skali ujęć syntetyzujących;

\footnotetext{
${ }^{2}$ Kostrzewski 1928; Kośko 1998.

${ }^{3}$ Żak 1972, 22 n.
} 
poprzez potrzebę odwołań do ośrodków wschodniosłowiańskich - m.in. w trybie politycznie poprawnej tezy o ich równoważności względem Cywilizacji Zachodu (por. inicjatywy Instytutu Badań Starożytności Słowiańskich czy też periodyku „Slavia Antiqua”, a zwłaszcza dorobek byłego dyrektora Instytutu Prahistorii Profesora W. Hensla, późniejszego Twórcy koncepcji „Międzynarodowej Unii Archeologii Słowiańskiej”4).

Gorset zawężenia tematycznego czasów akcji millenialnej uległ osłabieniu około roku 1966; inspirujące znaczenie miał tutaj postulat nowego podziału zadań poznawczych: na osnowie tzw. metody mikrogeograficznej zgłoszonej przez Witolda Hensla ${ }^{5}$. W przypadku ówczesnej Katedry Archeologii Uniwersytetu im. Adama Mickiewicza najpełniejszą reakcją na ów zaczyn był ,program kujawski” Pani Profesor Aleksandry Cofta-Broniewskiej (szczególnie dynamicznie rozwijany w latach 70. i 80. XX w.) ${ }^{6}$. Trudno w tym miejscu o szczegółowy zapis wymiaru inspiracji poznawczych, jaki zawdzięczamy Ekspedycji Kujawskiej - Zespołowi Badań Kujaw (por. syntezy prahistorii tego mezoregionu ${ }^{7}$ ). Ograniczę się do stwierdzenia, iż program badań kujawskiego mezoregionu osadniczo-kulturowego dokumentował złożony zapis wielokierunkowych uzależnień rozwojowych pogranicza dorzeczy Odry i Wisły ${ }^{8}$. Szczególnie istotnym poszerzeniem w stosunku do tradycyjnej narracji przyjmowanej w prahistorii rzeczonego obszaru były nader wyraziste markery więzi pontyjskich: wśród cyklu tzw. kultur środkowoeuropejskich, począwszy od V/IV tysiąclecia p.n.e. (kultury pucharów lejkowatych - grupy wschodnia, a zwłaszcza mątewska; kultury amfor kulistych, horyzontu Linin, horyzontu

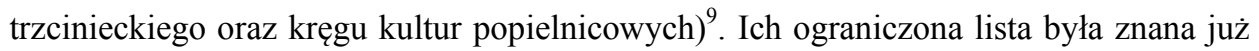
wcześniej, dotyczyła jednak głównie zjawisk późniejszych - z poziomu prologu epoki żelaza, np. w ujęciach pontyjskich marszrut „wczesnogermańskich kultur”, jastorfskiej czy wielbarskiej (m.in. Bastarnowie i Goci).

W latach 70. i 80. XX w., kiedy dokonywano sygnalizowanych ocen, istniała silna bariera polityczna hamująca realizację naturalnego $\mathrm{w}$ tej sytuacji międzynarodowego programu badawczego: archeologii pogranicza Zachodu i Wschodu Europy (w skrócie archeologii Międzymorza). Jej ilustracją może być fakt zakwestionowania w roku 1983 - na poziomie konsultacji ministerialnych - inicjatywy Instytutu Prahistorii podpisania umowy pomiędzy Uniwersytetem im. Adama Mickiewicza a Instytutem Archeologii Nacjonalnej Akademii Nauk Ukrainy, jako wadliwej organizacyjnie, tj. zawartej pomiędzy instytucjami o rozbieżnych funkcjach społecznych.

\footnotetext{
${ }^{4}$ Pierwszy Kongres Archeologii Słowiańskiej odbył się w Warszawie w dniach 14-18 września 1965 r.; por. Hensel 1968 (red.).

${ }^{5}$ Hensel 1971, s. 461 n.; por. ogląd koncepcji ,metody mikrogeograficznej”: Cofta-Broniewska 1988, s. $15-17$.

${ }^{6}$ Cofta-Broniewska 1988.

${ }^{7}$ Cofta-Broniewska, Kośko 1982; 2002.

${ }^{8}$ Cofta-Broniewska 1988 (red.); Kośko, Bednarczyk 1996 (red.).

${ }^{9}$ Kośko 1981; 1988, s. 173 n.; 1990; 1991; Domańska 1990.
} 


\section{SZANSE POZNAWCZE „STUDIÓW WSCHODOZNAWCZYCH” W CZASACH PO ROZPADZIE „ŻELAZNEJ KURTYNY”}

Realna cezura prologu efektywnego rozwoju rzeczonej opcji badawczej przypada stąd na czas wydarzeń politycznych z lat 1989-1991. W Europie dostrzec można było ówcześnie zaczyn nowego skonfigurowania podziału zadań badawczych, odpowiadającego szansom i potrzebom „postzimnowojennej epoki”; przewartościowania inspirowanego przez niektóre środowiska uniwersyteckie, przy czytelnym jednak wsparciu finansowym ze strony Państw. W wymiarze archeologicznym jako przypadek szczególnie wyrazisty wymienić należy np. niemiecką inicjatywę powołania do życia Instytutu Archeologii Eurazji (Deutsches Archäologisches Institut Eurasien-Abteilung). Polska reakcja na ów przełom świadomościowy, mając na uwadze zwłaszcza nasze usytuowanie geopolityczne, nie może stąd w pełni zadawalać ${ }^{10}$.

Ocena negatywna dotyczy braku wkomponowania środowiskowej oferty intelektualnej (także i potencjału kadrowego) w projekt ,polityki wschodniej” Państwa. Wyjątkiem - który niestety należy do przeszłości - pozostaje próba opracowania takiej koncepcji i jej realizacji podjęta w obrębie środowiska intelektualnego Ośrodka Ochrony Dziedzictwa Archeologicznego; funkcjonującego latach 2002-2006 w ramach urzędu Generalnego Konserwatora Zabytków RP. Powołano ówcześnie tzw. sekcję wschodnią, której zawdzięczamy m.in. projekty: Archeologicznego Zdjęcia Białorusi i Archeologicznego Zdjęcia Ukrainy; serii konferencji „Archeologiczna wspólnota kulturowa państw pogranicza” (2004 - Hajnówka: „Wspólnota dziedzictwa kulturowego ziem Białorusi i Polski; 2005 - Łańcut: „Wspólnota dziedzictwa archeologicznego ziem Ukrainy i Polski”) ${ }^{11}$; ,pogranicznych" cykli wydawnictw: stanowisk i regionów reperowych (por. finansowanie przygotowań do druku cmentarzyska w Prorvie ${ }^{12}$ ) oraz opracowań i wydawnictw kolekcji muzealnych (np. „plan Grodno”). W konstrukcji rzeczonego środowiska intelektualnego trudno nie dostrzec wpływu archeologów związanych z Instytutem Prahistorii Uniwersytetu im. Adama Mickiewicza; co dotyczy głównie „środowiska kujawskiego".

W latach III Rzeczypospolitej w konstrukcji modułu aplikacji archeologii w polityce zagranicznej Państwa nadal zdecydowanie dominował nurt bliskowschodni. Bliski Wschód - traktowany jako matecznik cywilizacyjny - zapewniał automatyczne medialne wsparcie inicjatyw dotowanych przez Ministerstwo Kultury i Dziedzictwa Narodowego i Ministerstwo Spraw Zagranicznych; tj. dokonań badawczych, a zwłaszcza konserwatorskich. Począwszy od wojny w Iraku, bliskowschodni nurt konserwatorski uległ wzmocnieniu. Warto zarazem odnotować wybitną rolę w tym ostatnim procesie młodych przedstawicieli poznańskiego środowiska archeologicznego.

\footnotetext{
${ }^{10}$ Por. przegląd polskich inicjatyw badawczych na Ukrainie: Lech, Partyka 2001 (red.).

${ }^{11}$ Gierlach, Kośko, Kaleczyc 2004 (red.); Gierlach 2007 (red.).

${ }^{12}$ Krywalcewicz 2007.
} 


\section{POZNAŃSKO-KIJOWSKI PROGRAM BADAŃ POGRANICZA BIOKULTUROWEGO ZACHODU I WSCHODU EUROPY}

Proces formowania się nowej strategii poznańskich zainteresowań pograniczem biokulturowym Zachodu i Wschodu Europy w wymiarze prawnym inicjowała umowa zawarta pomiędzy UAM (ściślej pomiędzy Instytutem Prahistorii i Instytutem Wschodnim, jako wnioskodawcami) a Instytutem Archeologii Nacjonalnej Akademii Nauk Ukrainy w Kijowie z 7 kwietnia 1992 r. (ryc. 1: 3). W początkowych latach jej funkcjonowania (lata 90. XX w.) realizowano na tej osnowie ,projekty przystosowawcze”: korespondencji języków taksonomii, aplikacji chronometrii radiowęglowej - jako języka analiz porównawczych; zastosowania (wykorzystania szans) metod badań specjalistycznych oraz rozpoznania ram zbliżenia teoretycznego ${ }^{13}$. Warto zaznaczyć, iż po przeglądzie ofert naukowych obu stron osiągnięto stan równowagi w wykonawstwie wyżej wymienionych projektów (mówiąc wprost: zidentyfikowaliśmy bardzo cennych intelektualnie i organizacyjnie partnerów). Nie mogło to natomiast dotyczyć wymiaru równowagi w ich finansowaniu, gdzie dominowały fundusze polskie (granty Komitetu Badań Naukowych, a następnie Departamentu Instrumentów Polityki Naukowej Ministerstwa Nauki i Szkolnictwa Wyższego; dofinansowania Fundacji UAM - ze środków wypracowanych przez pracowników Instytutu Prahistorii na trasach ,inwestycji liniowych” i marginalnie władz Uniwersytetu im. Adama Mickiewicza).

Do 2000 r. nie podejmowaliśmy wspólnych badań terenowych, postrzegając, że cezura ich prologu winna być określana przez stan zbliżenia konceptualnego $\mathrm{w}$ odczycie prahistorii „pogranicza”, rzutującego na optymalizację wyborów problematyk oraz miejsc eksploracji1 ${ }^{14}$. Dotychczasowe inicjatywy - począwszy od roku 2000 - miały głównie charakter rozpoznawczy i dotyczyły ważkich odnośnie do wybranych ram problematycznych stanowisk w zlewniach: Bohu (obiekt kurhanowy w Peczerze - 2000; kierownicy Wiktor I. Kłoczko i Piotr Chachlikowski); Horynia (wychodnie bazaltów i miedzi - 2000; kierownicy Wiktor I. Kłoczko i Piotr Chachlikowski; ryc. 1: 4) i Teterewu (hipotetyczna osada obronna-obiekt obrzędowy? kultury trypolskiej - 2004, kierownicy Wiktor I. Kłoczko i Aleksander Kośko). Przeprowadzono nadto rozległą kwerendę muzealną i paramuzealną na obszarze województw (oblasti): winnickiego oraz częściowo chmielnickiego i mikołajewskiego w ramach projektu ,szlak Bug-Boh (2003 r. - kierownicy Wiktor I. Kłoczko, Michał Potupczik oraz Aleksander Kośko i Marcin Igna-

\footnotetext{
${ }^{13}$ Kośko 2001 (red.); Kloczko, Kośko 2008.

${ }^{14}$ Warto odnotować fakt, iż paralelnie podejmowane ,pontyjskie projekty” innych polskich instytucji naukowych (por. przyp. 10) oparte były w zdecydowanej większości na koncepcji wyboru bardzo konkretnych, nośnych poznawczo w wymiarze europejskim, problemów i diagnostycznych dlań obiektów: w wymiarze inwestycji terenowych (np. paleolitu, czy też cywilizacji epoki żelaza: greckiej i scytyjskiej). Z tej perspektywy najwięcej cech zbieżnych z omawianym programem wykazuje program krakowsko-rzeszowsko-lwowski, inspirowany dorobkiem Profesora Jana Machnika: interkulturowego rozpoznania epok neolitu - eneolitu i brązu w rejonie pogranicza zlewni Wisły i Dniestru.
} 
czak). W latach 2009-2010 zainicjowano trzy cykle długofalowych prac badawczych: w zlewni Dniestru (cmentarzysko kurhanowe w Bukównie; kierownicy Igor Koczkin, Sergiej Lysenko i Przemysław Makarowicz) oraz w zlewni Bohu (grodzisko w Sewerinowce; kierownicy Jurij Boltrik i Marcin Ignaczak). Rejestr „dokonań pontyjskich” Instytutu Prahistorii należy dopełnić o kooperatywne z Instytutem Historii UAM prace wykopaliskowe w Chersonesie (lata 2003-2004, współkierownik Józef Bednarczyk) (ryc. 1: 6). W realizacji wyżej wymienionych planów prac wykopaliskowych wykorzystywano głównie dotacje Fundacji UAM (por. wcześniejsze uwagi o roli w zakresie pozyskiwania tychże środków finansowych pracowników Instytutu Prahistorii). Istotną ofertę zbliżenia metodycznego w wymiarze badań terenowych stworzyła ,,archeologia autostradowa", a ściślej szanse, jakie generowała dla zaistnienia wspólnej poznańskokijowskiej ekspedycji powołanej do badań na stanowisku Grabkowo 10 - AUT 131 (kierownicy Bartosz Józwiak i Michał Widejko; ze strony ukraińskiej w pracach wykopaliskowych uczestniczyło ośmiu archeologów) ${ }^{15}$.

Projekt poznańsko-kijowski był przez okres pierwszej dekady III Rzeczpospolitej i pozostaje - jak mniemam także i obecnie - najszerszą platformą promocji dorobku wielu ośrodków „,archeologii Międzymorza”, szansą na ekspozycję badań danej problematyki w ogólnoeuroazjatyckiej skali, ponad barierami regionalnymi. Jego międzynarodowym wyróżnikiem stało się powołanie w 1993 r. periodyku (w wersji wyjściowej serii) „Baltic-Pontic Studies” (do roku 2010 ukazało się 15 tomów), wydawanego w jezyku angielskim. Pozycja ta zyskała trwałe miejsce na europejskim rynku kontynuatywnych wydawnictw archeologicznych (por. oceny punktowe w skali listy HERA: 2007). Koncepcja Baltic-Pontic Studies zakładała :

- wyodrębnianie problemów kluczowych (w trybie międzyośrodkowych uzgodnień),

- przeglądy stanów ich realizacji w kręgu ośrodków naukowych ,pogranicza”,

- wspomaganie redukcji zapóźnień (finanse KBN),

- zamawianie pożądanych opracowań i ich międzynarodową ekspozycję.

W dotychczasowym dorobku periodyku rzeczona ekspozycja dotyczyła agraryzacji $^{16}$, nomadyzmu i pastoralizmu ${ }^{17}$, stref pogranicza w ekumenie społeczności kultury trypolskiej $^{18}$, kultury amfor kulistych ${ }^{19}$, kultury katakumbowej ${ }^{20}$, kręgu kultury trzci-

\footnotetext{
${ }^{15}$ Program ów firmowany merytorycznie przez pracowników Instytutu Archeologii Uniwersytetu im. Adama Mickiewicza realizowany był pod szyldem organizacyjnym porozumienia (a następnie umowy sygnowanej w 2001 r.) zawartego pomiędzy Fundacją UAM - Centrum Badań Archeologicznych a Instytutem Badań Naukowych Ochrony Zabytków Ministerstwem Kultury i Sztuki Ukrainy (koordynatorzy Aleksander Kośko i Wiktor I. Kłoczko).

${ }^{16}$ Domańska, Jacobs 1998 (red.). Projekt realizowany przez Instytut Archeologii Uniwersytet Łódzkiego, przy wsparciu finansowo-edytorskim Fundacji UAM.

${ }^{17}$ Kośko 1994 (red.).

${ }^{18}$ Kośko 1995 (red.); Ko śk o 2000 (red.).

${ }^{19}$ Kośko 1996 (red.); Szmyt 1999.

${ }^{20}$ Ślusarska 2006.
} 
nieckiej $^{21}$, chronometrii radiowęglowej ${ }^{22}$, szlaków strefy pogranicza ${ }^{23}$, diagnostycznych cech kultury, uzbrojenia ${ }^{24}$ oraz aplikacji motywu sznura w ornamentyce ceramiki ${ }^{25}$.

Pod koniec lat 90 . XX w. ofertę omawianego dialogu wzbogaciły seryjne sympozja z zakresu problematyki archeologii międzymorza:

- 1997 r. Obrzycko „Trzciniec - kultura archeologiczna, czy interkulturowy proces?"

-2000 r. Brześć Białoruski „Od neolityzacji do początków epoki brązu”26

- 2003 r. Obrzycko „Nomadyzm a pastoralizm w międzyrzeczu Wisły i Dniepru. (neolit, eneolit, epoka brązu)"

- 2008 r. Obrzycko „Szlaki Międzymorza: Bałtyk- Bug-Boh-Pont”.

Dla celów ekspozycji dorobku sympozjalnego oraz prac inspirowanych przez ów dorobek powołano do życia serię wydawnictw o nazwie „Archeologia Bimaris” (teksty są tutaj publikowane w językach narodowych autorów, ze streszczeniami w języku angielskim), która mieści w sobie dwa cykle: dyskusje (do roku 2010 opublikowano 3 tomy, a 4 został złożony do druku ${ }^{27}$ ) oraz monografie (do roku 2010 opublikowano 4 tomy $^{28}$ ).

\section{CO DALEJ?}

Pytanie to winno dotyczyć tak perspektyw (a) programowych, jak i (b) organizacyjnych. W tym drugim przypadku istnieje szeroki zakres uwarunkowań zewnętrznych: spoza zasięgu intencji środowiska dotychczasowych realizatorów programu, których szersza analiza wykracza poza ramy prezentowanego artykułu.

a. Najbardziej czytelnym zwornikiem programowym wspólnych inicjatyw badawczych ośrodków archeologicznych Międzymorza są obecnie studia nad autogenezą szlaków; szerzej ujmując stref intruzji, przebiegu szlaków oraz infrastruktury dróg na obszarze pogranicza Wschodu i Zachodu Europy (ryc. 2). Ogólnie, w centrum zainteresowania

${ }^{21}$ Ko śko 1998 (red.).

${ }^{22}$ Kośko 1999 (red.); Kośko, Klochko 2003 (red.).

${ }^{23}$ Kośko 2002; Kośko, Klochko 2009 (red.).

${ }^{24}$ Klochko 1993, 2001.

${ }^{25}$ Kośko, Szmyt 2010 (red.).

${ }^{26}$ Badania realizowane na osnowie umowy o współpracy naukowej pomiędzy Uniwersytetem im. Adama Mickiewicza (wnioskodawca: Instytuty Antropologii, Historii, Prahistorii i Wschodni) a Instytutem Historii Akademii Nauk Białorusi (wnioskodawca: Wydziały Archeologii Epoki Kamienia i Brązu, Archeologii Epoki Żelaza oraz Archeologii Średniowiecza), podpisanej 3 kwietnia 1996 r. (koordynatorzy: Janusz Piontek, Janusz Czebreszuk, Krzysztof Pietkiewicz, Marzena Szmyt oraz Michał Czarniawski).

${ }^{27}$ Kośko, Czebreszuk 1998 (red.); Czebreszuk, Kryvalcevič, Makarowicz 2001 (red); Kośko, Szmyt 2004 (red.); Ignaczak, Kośko, Szmyt 2011 (red.).

${ }^{28}$ Czebreszuk 2001; Krywalcewicz 2007; Makarowicz 2010; Pietrzak 2010. 


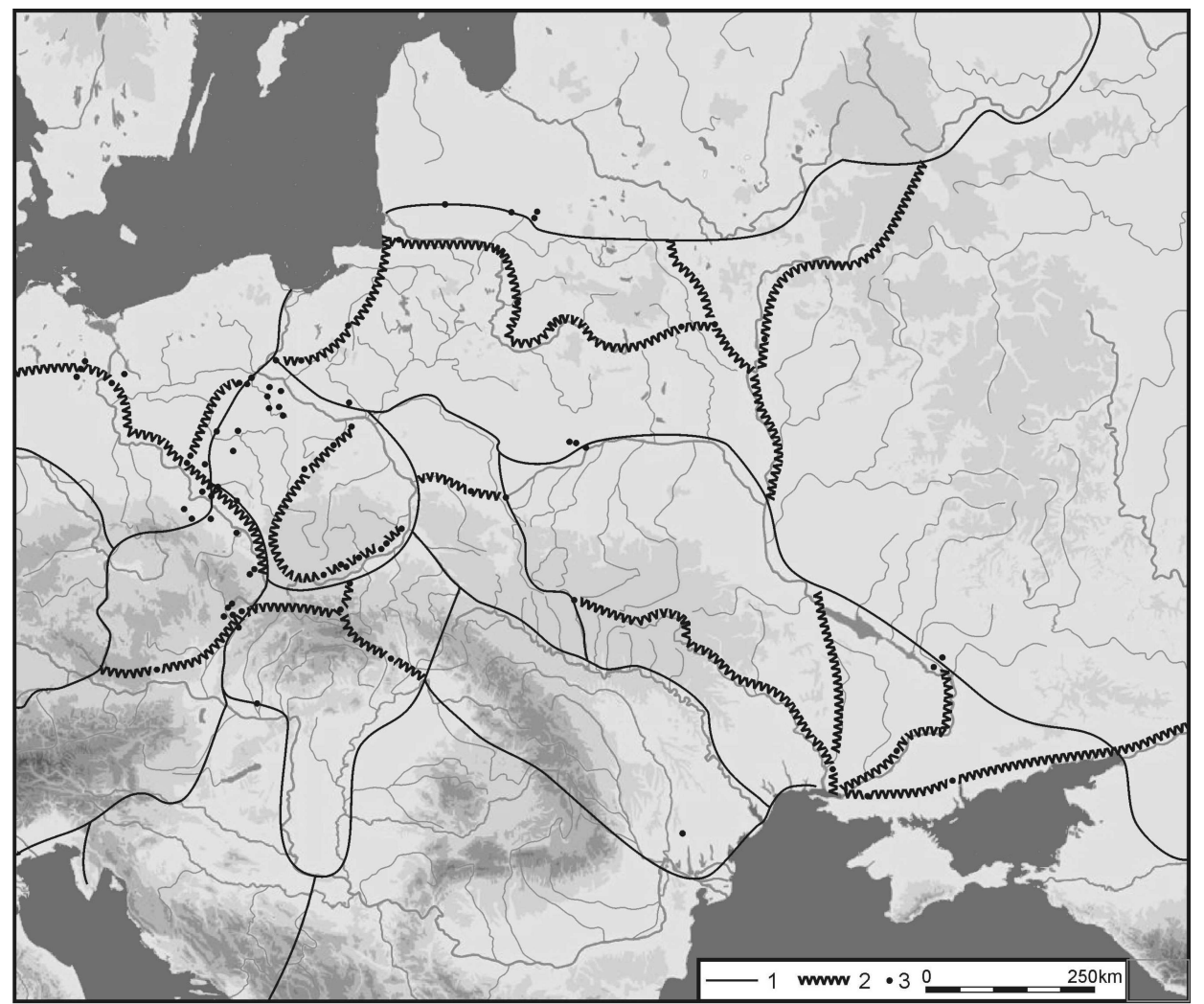

Ryc. 2. Sieć szlaków w strefie pogranicza biokulturowego Zachodu i Wschodu Europy w okresie od IV/III do II tysiąclecia przed Chr.

Legenda: 1 - rozgraniczenie fizyczno-geograficzne Zachodu i Wschodu Europy (tzw. limes bużański - dniestrzański); 2 - sieć szlaków w ujęciu M. Gimbutas; 3 - sieć szlaków w ujęciu A. Kośki. Zob. Ignaczak, Kośko, Szmyt 2011

pozostają procesy komunikacji, tak w wymiarze sygnalizowanych przesłanek empirycznych, jak i w zakresie teoretycznych kontekstów: postrzegania ich społecznych funkcji ${ }^{29}$. Powyższą ocenę, uzasadnioną w pierwszym rzędzie stanem zaangażowania naukowego środowisk archeologicznych, wspierają także i współczesne racje regionalnych społeczności, zgłaszane względem naszej dyscypliny. Naturalnym rozwinięciem tego nurtu refleksji programowej pozostaje projekt „Atlasu Litycznych Form Insygnialnych”; tworzony obecnie przy współudziale poznańskiego środowiska archeologicznego ${ }^{30}$. Inny, istotny projekt

${ }^{29}$ Bednarczyk, Czebreszuk, Makarowicz, Szmyt 2008.

${ }^{30}$ Zarys koncepcji „Atlasu Litycznych Form Insygnialnych” (w innym, możliwym sformułowaniu: przedmiotów prestiżowych) wyróżniającej ze zbioru ogółu wytworów z krzemienia i kamienia (identyfikowanych na terytoriach Polski, Białorusi i Ukrainy) podzbiór artefaktów okazjonalnych, tj. niewiązanych w praktyce interpretacji funkcjonalnej z doświadczeniem codzienności, „zajęć przydomowych” - postał na sympo- 
badawczy wynikający z rzeczonej oceny zawarty jest w umowie pomiędzy Uniwersytetem im. Adama Mickiewicza w Poznaniu a Państwowym Mikołajewskim Uniwersytetem im. W. O. Suchomlińskiego w Mikołajewie. W planie naukowym eksponowano interdyscyplinarne badania ważnych odcinków szlaków Międzymorza: ujść Bohu - Ingułu oraz Dniepru $^{31}$ (ryc. 1: 3). Listę nowych inicjatyw organizacyjnych dopełnia program badań „,szlaków karpacko-naddniestrzańskich" w epoce brązu, oparty na umowie zawartej pomiędzy Uniwersytetem im. Adama Mickiewicza a Narodowym Uniwersytetem Przykarpackim im. Wasyla Stefanyka w Iwano-Frankiwsku ${ }^{32}$. Zakładamy, że w ramach tak zarysowanej ,węzłowej problematyki” szczególne znaczenie zyska okres IV/III-I tysiąclecia p.n.e., tj. czas prologu systemu szlaków i dróg, z zastosowaniem wozu, a następnie konia - jako zwierzęcia jucznego oraz do jazdy wierzchem ${ }^{33}$. Tych też czasów dotyczą, sygnalizowane już wcześniej, bieżące programy badań terenowych w rejonie Podola.

b. Problemy z kontynuacją zarysowanych inicjatyw poznawczych mają przede wszystkim wymiar organizacyjny, dotycząc listy szans na uzyskanie dotacji dla ich dalszej realizacji; tak ze strony władz Uniwersytetu im. Adama Mickiewicza, jak i krajowych oraz międzynarodowych gremiów: ważących na podziale środków przeznaczonych na naukę. Wiąże się z tym potrzeba programu promocji eksponowanych $\mathrm{w}$ tym artykule inicjatyw poznawczych.

Konkretyzując, należy sformułować i upowszechniać ogólnohumanistyczny przekaz, iż program archeologii międzymorza winien być sytuowany na liście kluczowych zagadnień badawczych współczesnej Europy; jako komponent interdyscyplinarnych studiów nad genezą rozwoju węzłowej strefy granicznej w jej aktualnym zróżnicowaniu kulturowym.

Zjawiskiem pożądanym byłoby, aby ośrodki archeologiczne uczestniczące w realizacji rzeczonego programu zyskały szansę współtworzenia stowarzyszeń realnie operatywnych - poprzez zadaniowe mechanizmy prawne - $\mathrm{w}$ dialogu $\mathrm{z}$ inicjatorami szerszych organizacyjnie konstrukcji - międzyregionalnych i międzypaństwowych - zorientowanych na rzecz obywatelskiego, ekonomicznego i politycznego zbliżenia Państw Międzymorza.

zjum w Obrzycku w październiku 2008 r. (por. Kośko, Klochko 2009, red.). Dalsze prace, dyskusję nad jego konkretyzacją rzeczonego projektu przeniesiono na forum Komisji Schyłku Neolitu i Początku Epoki Brązu Komitetu Nauk Pra- i Protohistorycznych PAN (etapowe omówienia wyników prac przygotowawczych prowadzono na kolejnych zebraniach w kwietniu - w Warszawie i w czerwcu - w Lublinie 2010 r.). Podsumowania dyskusji dokonano na międzynarodowym sympozjum „Na rubieży kultur” w Supraślu w listopadzie 2010 r. (por. Stankiewicz, Wawrusiewicz 2011, red.).

${ }^{31}$ Umowa, powstała z inicjatywy Instytutu Prahistorii UAM i Instytutu Historii i Politologii PMUWOS, podpisana 23.07.2010 r., deklaruje ,współpracę w zakresie tematyki „Archeologii Niziny Bohu-Dniepru, Szlaków Pont-Bałtyk” (koordynatorzy: Danuta Minta-Tworzowska, Aleksander Kośko, Marcin Ignaczak oraz Walerij Budzak, Jurij Hrebennikow i Kyruło Horbenko).

${ }^{32}$ Umowa, powstała z inicjatywy Instytutu Prahistorii UAM i Instytutu Historii i Politologii NUPWS Ivano-Frankivsku, podpisana w 2009 r. (koordynatorzy: Przemysław Makarowicz oraz Igor Koczkin).

${ }^{33}$ Czebreszuk, Kośko, Szmyt 2008. 


\section{BIBLIOGRAFIA}

Bednarczyk J., Czebreszuk J., Makarowicz P., Szmyt M. (red.)

2008 Na pograniczu światów. Studia z pradziejów międzymorza bałtycko-pontyjskiego ofiarowane Profesorowi Aleksandrowi Kośko w 60. rocznicę urodzin, Poznań.

Cofta-Broniewska A.

1988 Metodyka badań regionalnych na Kujawach, (w:) Kontakty pradziejowych społeczeństw Kujaw z innymi ludami Europy, red. A. Cofta-Broniewska, Inowrocław, s. 15-27.

Cofta-Broniewska A. (red.)

1988 Kontakty pradziejowych społeczeństw Kujaw z innymi ludami Europy, Inowrocław.

Cofta-Broniewska A., Kośko A.

1982 Historia pierwotna społeczeństw Kujaw, Warszawa-Poznań.

2002 Kujawy w pradziejach i starożytności, Inowrocław-Poznań.

Czebreszuk J.

2001 Schyłek neolitu i początki epoki brązu w strefie południowo-zachodniobałtyckiej (III i początki II tys. przed Chr.). Alternatywny model kultury, „Archaeologia Bimaris”. Monografie, t. 1, Poznan

Czebreszuk J., Kośko A., Szmyt M.

2008 The Horse, Wagon and Roads. Cultural Resources used by Early Agrarian Societies in the Drainages of the Vistula and Oder Rivers, (w:) Proischożdenie i rasprostranenie kolesniczestva, Lugansk, s. 47-54.

Czebreszuk J., Kryvalcevič M., Makarowicz P. (red.)

2001 Od neolityzacji do początków epoki brazu. Przemiany kulturowe w międzyrzeczu Odry i Dniepru między VI i II tys. przed Chr., „Archaeologia Bimaris”. Dyskusje, t. 2, Poznań.

Domańska L.

1990 Kaukasko-nadczarnomorskie wzorce kulturowe w rozwoju późnoneolitycznych społeczeństw Niżu Polski strefy pogranicza Europy Wschodniej i Środkowej, Inowrocław.

Domańska L., Jacobs K. (red.) 1998 Beyond Balkanization, „Baltic-Pontic Studies”, vol. 5.

Gierlach M. (red.)

2007 Wspólnota dziedzictwa archeologicznego ziem Ukrainy i Polski, Warszawa.

Gierlach M., Kośko A., Kaleczyc A. (red.)

2004 Wspólnota dziedzictwa kulturowego ziem Białorusi i Polski, Warszawa.

Hensel W. (red.)

1968 I Międzynarodowy Kongres Archeologii Słowiańskiej, Wrocław-Warszawa-Kraków.

Hensel W.

1971 Archeologia i prahistoria, Wrocław.

Klochko V. I.

1993 Weapons of the Northeren Pontic Zone in the 16th - 10th Centuries BC, „Baltic-Pontic Studies”, vol. 1.

2001 Weaponry of Societes of the Norhern Pontic Culture Circle: 5000-700 BC, „Baltic-Pontic Studies”, vol. 10.

Kloczko V. I., Kośko A.

2008 Do pjatnadcjatiriczja tvorczoj spivpraci Institutu archeologii NAN Ukrajini z Insitutom prahistorii Poznanskogo universitetu, „Materijali ta doslidżennja z archeologii Schidoj Ukrajini”, t. 8, s. 320-328

Kostrzewski J

1928 Groby neolityczne ze szkieletami skurczonymi w Białym Potoku (w pow. czortkowskim) „Przegląd Archeologiczny”, t. 3, s. 9-18.

Kośko A.

1981 Udział południowo-wschodnioeuropejskich wzorców kulturowych w rozwoju niżowych społeczeństw kultury pucharów lejkowatych, Poznań. 
1988 Rozwój kulturowy społeczeństw Kujaw w okresie późnego neolitu oraz interstadium epok neolitu i brązu w aspekcie recepcji egzogennych wzorców kulturotwórczych, (w:) Kontakty pradziejowych społeczeństw Kujaw z innymi ludami Europy, red. A. Cofta-Broniewska, Inowrocław, s. 145-183.

1990 The Migration of Steppe and Forest-steppe Communities into Central Europe, „The Journal of IndoEuropean Studies", vol. 18-3-4, s. 309-329.

1991 The Vistula-Oder Basins and the North Pontic Region, „The Journal of Indo-European Studies”, vol. 19-3-4, s. 235-257.

1998 Koszilovecka tema u naukovij programi Józefa Kostrzewskiego, (w:) Tripilske poselennja Koszilivci - Oboz, red. V. I. Olijnik, Zaliszcziki, s. 14-15.

2001 Zarys historii i perspektyw rozwoju poznańsko-kijowskiego programu studiów nad prehistorią battycko-pontyjskiego międzymorza, (w:) $Z$ archeologii Ukrainy i Jury Krakowskiej, red. J. Lech, J. Partyka, Ojców, s. 441-446.

Kośko A. (red.)

1994 Nomadism and Pastoralism in the Circle of Baltic-Pontic Early Agrarian Cultures: 5000-1650 BC, „Baltic-Pontic Studies”, vol. 2.

1995 Cemeteries of the Sofievka type: 2950-2750 BC, „Baltic-Pontic Studies”, vol. 3.

1996 Eastern Exodus of the Globular Amphora People: 2950-2350 BC, „Baltic-Pontic Studies”, vol. 4.

1998 The Trzciniec Area of the Early Bronze Age Civilization: 1950-1200 BC, „Baltic-Pontic Studies”, vol. 6 .

1999 The Foundations of Radiocarbon Chronology of Cultures between the Vistula and Dnieper: 3150 1850 BC, „Baltic-Pontic Studies”, vol. 7.

2000 The Western Border Area of the Tripolye Culture, „Baltic-Pontic Studies”, vol. 9.

2002 Fluted Maces in the System of Long-Distance Exchange Trails of the Bronze Age: 2350 - 800 BC, „Baltic-Pontic Studies”, vol. 11.

Kośko A., Bednarczyk J. (red.)

1996 Z badań nad genezą regionalizmu kulturowego społeczeństw Kujaw, Poznań-KruszwicaInowrocław.

Kośko A., Czebreszuk J. (red.)

1998 „Trzciniec”: system kulturowy czy interkulturowy proces? „Archaeologia Bimaris”. Dyskusje, t. 1, Poznań.

Kośko A., Klochko A. (red.)

2003 The Foundations of Radiocarbon Chronology of Cultures between the Vistula and Dnieper: 4000 1000 BC, „Baltic-Pontic Studies”, vol. 12.

2009 Routes between the Seas: Baltic-Bug-Boh-Pont from the $3^{\text {rd }}$ to the Middle of the $1^{\text {st }}$ Millennium BC, „Baltic-Pontic Studies”, vol. 14.

Kośko A., Szmyt M. (red.)

2004 Nomadyzm a pastoralizm w międzyrzeczu Wisly i Dniepru (neolit, eneolit, epoka brązu), „Archaeologia Bimaris". Dyskusje, t. 3, Poznań.

2010 'Cord' Ornaments on Pottery in the Vistula and Dnieper Interfluvial Region: $5^{\text {th }}-4$ th Mill. BC, „Baltic-Pontic Studies”, vol. 15.

Krywalcewicz M.

2007 Prorva. Cmentarzysko z połowy III - początku II tysiąclecia przed Chr. na górnym Naddnieprzu, „Archaeologia Bimaris". Monografie, t. 2, Poznań.

Lech J., Partyka J. (red.)

2001 Z archeologii Ukrainy i Jury Ojcowskiej, Ojców.

Makarowicz P.

2010 Trzciniecki krąg kulturowy - wspólnota pogranicza Wschodu i Zachodu Europy, „Archaeologia Bimaris". Monografie, t. 3, Poznań. 
Pietrzak S.

2010 Zastosowanie $i$ technologie wytwarzania dziegciu przez społeczeństwa międzyrzecza Dniepru $i$ Laby od VI do II tysiąclecia BC, „Archaeologia Bimaris”. Monografie, t. 4, Poznań.

Stankiewicz U., Wawrusiewicz A. (red.)

2011 Na rubieży kultur. Badania nad okresem neolitu $i$ wczesnej epoki brązu, Białystok

Szmyt H.

1999 Between West and East People of The Globular Amphora Culture in Eastern Europe: 2950-2350 BC, „Baltic Pontic Studies”, vol. 8.

Ślusarska K.

2006 Funeral Rites of the Catacomb Community: 2800-1900 BC, Ritual, Thanatology and Geographical Origins, „Baltic Pontic Studies”, vol. 1.

$\dot{\mathrm{Z}} \mathrm{ak} \mathrm{J}$.

1972 Zarys dziejów poznańskiego ośrodka archeologicznego, (w:) Problemy badań archeologicznych Polski Północno-Zachodniej. Materiały z Sesji Naukowej zorganizowanej z okazji 50-lecia Katedry Archeologii Pradziejowej i Wczesnidziejowej UAM, Poznań, 20-21 listopada 1969 roku, red. J. Żak, Poznań, s. 15-38.

Aleksander Kośko

Instytut Prahistorii, Uniwersytet im. Adama Mickiewicza ul. Św. Marcin 78, 61-809 Poznań, Poland 